\title{
Utilizing learning theories in the digital age: an introduction for health librarians
}

\author{
Dean Giustini
}

\section{Key messages}

(i) Many health librarians are successful, intuitive teachers but increasingly recognize the need to employ new teaching approaches

(ii) Most health librarian-led teaching takes place in classrooms, at reference desks, and online (using chat, tutorials, and Web 2.0 tools)

(iii) In the digital age, how we teach may be as important as what we teach

(iv) Behaviourism, constructivism, and situated-learning are three learning theories presented to tailor teaching sessions to users' needs

(v) Insight into how learning occurs has implications for the successful design, delivery, and assessment of library programs circa 2008

\section{Introduction}

This paper is an introduction to learning theories for health librarians. In this column (part I of a teaching and learning series for the JCHLA / JABSC) I lay the foundation for the study of learning theories and examine three influential theories specifically: behaviourism, constructivism, and situated learning [1]. In subsequent columns, I will explore learning theories as a set of tools and strategies for the improvement of information literacy and teaching programs.

Throughout this series, I want to emphasize the importance of a "blended approach" to designing and evaluating our teaching, one that comprises experience, learning theory, and evidence from the literature. Learning theory is simply that: a tool in our teaching toolbox. Perhaps some of you are already using a blended approach to design instructional programs or some other hybrid methodology.

For those interested in deeper exploration of learning theories, I make suggestions for further reading whenever possible. The current research, for example, is worth a close review due to newer pedagogical theories such as connectivism and the idea of recontextualizing existing learning theory for Web 2.0 users [2]. However, I will begin by distilling the very basics of learning theory and by orienting readers to a few major theorists in the area.
These basic learning theories are difficult to grasp at times, but perseverance will bring rich rewards to those who put in the time and effort to understand them. Remember that learning theories are simply ideas-not to be followed slavishly but to consider for the insights they provide in (re)designing our work in the classroom. Health librarians looking to evaluate how they teach may find that they offer a good place to start.

\section{Background}

Much of the work of health librarianship depends on comprehensive knowledge of health information sources and services. In the context of reference services, health librarians spend a lot of time leading end-users to the evidence and do so at various physical and virtual library service points [35]. In a strategic sense, clinical librarians also lead users to the evidence in various contexts: face-to-face $(\mathrm{F} 2 \mathrm{~F})$ during ward rounds and on clinical teams [6].

As health librarians, we play a key role in getting the evidence to where clinicians and patients need it most: at-pointof-care [7]. But health librarians cannot facilitate this knowledge transfer alone and ultimately end-users must learn how to find the evidence for themselves. The ability to cumulate the evidence efficiently requires a growing list of digital skills and vigilance in keeping them current, so health librarians are never short of new things to teach.

Technology drives much of our teaching. But rather than performing searches for end-users (the way we used to), health librarians teach end-users information skills with varying levels of user retention and success. What are the reasons for a lack of retention and success related to our teaching? Does learning theory - and changes in the way end-users stay informed in the digital age-provide insight into this problem?

A recurring question in this discussion is what information literacy skills are most useful and worth teaching? Biomedical information skills run the gamut from navigating the newest interfaces to MEDLINE to searching for grey literature and managing citations in RefWorks. But not every clinician will have the time to learn these skills.

In the long view, how we teach will determine how successful we are in moving knowledge-translation forward. If

D. Giustini. Biomedical Branch Library, Gordon and Leslie Diamond Health Care Centre, 2775 Laurel Street, Floor 2, Vancouver, BC V5Z 1M9, Canada (e-mail: dean.giustini@ubc.ca). 
we want to be as competent at teaching as possible, we can increase our chances of success by understanding how knowledge is created in the digital age in the first place. It seems self-evident that our work will be increasingly ineffectual unless we can use a set of proven methodologies to optimize our time with end-users.

Interestingly, research into how librarians perceive their teaching roles suggests more than half $(>50 \%)$ feel some reluctance and discomfort about them [8]. One reason may be that most library and information science (LIS) programs have only recently begun to offer courses on teaching roles and few offer courses on pedagogical theory. It is not surprising some librarians feel ill-equipped to assume instructor roles and express a lack of proper theoretical training.

\section{How we teach is critical}

If our goal is to be better at teaching, how we teach in the digital age is just as important as what we teach. But this requires some sense of how learning takes place and how it shifts based on context. For two decades or more, health librarians have assumed teaching roles in their institutions [9]. Many have evaluated their programs and design classes based on what they feel works and what content they surmise is important.

But librarians need as many techniques in their teaching toolbox as possible, including a set of workable theories [10]. We face a host of challenges in getting our users' attention given the pressures of the age, lack of time, and the ubiquity and simplicity of Web searching.

Most importantly, we need to consider meeting our endusers where they practice, learn, and work, including embedding ourselves online. Health librarians will eventually want to consider a hybrid of face-to-face and digital methods to deliver programs in the Web 2.0 era.

\section{Five teaching skills for health librarians}

At least two health librarians have synthesized the evidence about instructional program delivery [11-12]. Other academic librarians, such as Peacock, McNamara, and Core, stress the importance of "sound pedagogical knowledge" in assuming teaching roles [13-14].

Many of the teaching skills (capabilities or knowledge sets) mentioned regularly fall into five categories:

(1) Basic knowledge of learning theories - Do you apply knowledge of learning theories into your teaching or use the same method each time (e.g., demonstration, "hands-on")

(2) Awareness of innovative teaching trends and pedagogical research - Do you integrate new ideas from the research into your teaching? Can you evaluate your teaching and undertake critical appraisal methods (evidence-based)?

(3) Competency using information technologies and social software - Do you follow trends in open access, scholarly publishing, and Web 2.0? Can you apply technologies or tools to specific problem-solving (e.g., blogs for reflective practice, digital outreach, wikis for collaboration)?
(4) Ability to design individual classes as part of overall information literacy programs - Do you gather information about users' skill levels before your classes? Are you familiar with the information literacy frameworks of the American Library Association (ALA) or the Association of American Medical Colleges (AAMC) [15-16]?

(5) Ability to evaluate instruction and publish research - Do you get regular feedback about your teaching (i.e., from participants and peers)? Have you thought of using a study methodology to evaluate your teaching (e.g., randomization, pre-test/post-test evaluation, case study)?

\section{Selecting a teaching approach}

There is nothing so practical as a good theory.

Kurt Lewin

Effective librarian-teachers consider several factors in selecting a teaching approach. Selecting a method based on the goals of a session and (or) type of classroom environment the instructor wants to create is important. So what teaching and learning techniques create a desirable environment in the classroom? Accordingly, the literature identifies a number of different pedagogical methods that can be used to promote various kinds of learning, and they are worth looking at in some detail.

One popular method-by modifying and directing desirable behaviours - is based on the idea that "knowledge" is an asset given to a learner by an expert in the area. The correct skills and behaviours are then reinforced by repeating main concepts and testing comprehension. This is where our examination of learning theory begins.

\section{What is behaviourism?}

Behaviourism is seeing observable changes in behaviours...patterns are repeated in learners until they become automatic [17].

Behaviourists believe that learning takes place when prompted by a stimulus and shaped by repetition/reinforcement [18]. By rewarding learners for a correct response, desirable behaviours are reinforced. In the stimulusreinforcement-consequences model, students know that mastering content presented by an expert will bring rewards. Many current educational systems are built on the beliefs of behaviourism.

But when students learn to please their teachers and stay on their "best behaviour", the motivation is to respond to cues and patterns in learning activities. Is it a good pedagogical approach to teach library users to seek specific cues in their searching or by offering incentives to master certain skills? It may well be; some educators say that they have their place. Others however have repeatedly suggested that this may be a limited approach if used exclusively [19].

A recurring theme in the literature is that competition between learners increases when a premium is put on achievement; some medical schools are so concerned about the implications of competition that they are looking at pass/fail assessment models as alternatives [19].

In post-secondary education, behaviourist models are linked to didactic lectures. Think of the way most professors teach, usually by lecturing as a "sage on the stage" [20]. 
Some lecturers are very entertaining and expert at public speaking but may not be as expert at teaching.

Sage-on-the-stage lecturing is a very efficient way to convey content for learners, particularly at conferences. But is lecturing the only way to convey content to a large group of people enrolled in a course? Lectures certainly have their place in learning, but some students suggest that if professors want to talk so much that they put their lectures on YouTube for later (re)viewing [21].

Prominent educational figures such as John Dewey, Jean Piaget, and others proposed alternate paradigms to behaviourism while acknowledging its place in our educational systems. Some of these formal and informal models are discussed throughout the teaching and learning series, such as Freire's Pedagogy of the oppressed [22], Vygotsky's Mind in society [23], and Lave and Wenger's Situated learning: legitimate peripheral participation [24], to name a few.

For now, let's turn our attention to some prominent names in behaviourism.

\section{Influential behaviourists}

Russian psychologist Ivan Pavlov (1849-1936), known for his work in classical conditioning, carried out behavioural experiments involving a dog, some food, and a bell [25]. During his experiments, he rang a bell a few times before his dog was given food and repeated it several times. After, Pavlov noticed that the dog salivated at the ringing of the bell alone.

Pavlov's experiment is the basis of all "classical" conditioning [26]. His model is seen as the first scientific study of measuring learned behaviour-think of it as an important reference point for understanding all subsequent theory. Interestingly, even though Pavlovian conditioning is considered by many to be an important behavioural concept, "Pavlov's dog" is used pejoratively by some to describe a person who reacts to situations rather than uses critical judgment.

American psychologist John B. Watson (1878-1958) established a variant of Pavlov's work called operant conditioning. Operant conditioning operates on conditions within a subject's environment [27]. To be more precise, Watson observed the behaviour of an infant boy, Albert, as a rabbit was introduced into his crib area or his play environment. Watson hit the crib several times while releasing the rabbit, which made the boy apprehensive (he cried). Thereafter, Albert developed a conditioned "emotional response" (fear) brought on by seeing the rabbit alone.

Published in 1920, Watson's "Little Albert Study" is seen as one of the most important studies in the 20th century of the central role that emotions play in learning [28]. His findings were later challenged on the grounds that conditioned fears (also known as avoidance learning) are not as permanent as Watson believed and could actually be reversed [29].

American psychologist B.F. Skinner (1904-1990) observed that rewards and punishments influence animal behaviour [30]. He noticed that a rat can learn how to push a lever in his cage to get a reward of food. However, if a second lever was pushed administering a mild electrical charge, the rat learned to avoid it. The idea of Skinner's "zap" led to other forms of negative reinforcement and aversion therapy for the treatment of homosexuality [31].
Skinner's research illustrates that rewards and punishment have a profound psychic impact on learning behaviour. Further, changes in behavior are the result of an individual's response to events (stimuli) that occur in the environment [30]. His research includes motivation and presenting information to learners in small bits to reinforce micro-behaviours and responses.

\section{Behaviourism and computer-assisted learning}

Many basic behavioural concepts can be applied to computer-assisted learning (CAL). Skinner, in fact, refers to machine-based learning in his own research [32]. One benefit of CAL is that complex material and vast amounts of information can be covered several times by learners. The idea of repetition is used by many librarian-instructors and within library tutorials to emphasize critical content, for example [33].

E-learning also helps students learn new skills on their own time. Some e-learners enjoy doing modules at their own pace and prefer the regular assistance provided by online instructors without having to attend actual classes.

Computer-assisted instruction (CAI) is an efficient teaching method for visual and kinesthetic learners - those who like to be involved "hands-on" in their learning [34]. One of the strengths of CAI is that individual differences can be acknowledged in module and course design; however, it must be said that not all learning styles can or will be accommodated.

Some gender research reveals a digital divide between boys who prefer computer learning and girls who prefer social learning. In using computers, boys are able to work through tutorials when they want and are not limited by the traditional classroom - a major benefit to them [35].

Positive reinforcement is used throughout the computer gaming world. As gamers learn advanced guild skills in World of Warcraft (WoW), they gain advantage over opponents. This is a reason why gaming is popular with some learners as it provides a strong motivation to learn new skills.

\section{Critique of behaviourist models}

When teachers lecture to students-and literally "download" information to them-they provide no time to discuss or challenge ideas. Some critics say that this is not learning for retention as much as listening to an expert speak. Many millennial and Internet generation students now expect opportunities to debate ideas because they have grown up digital and are part of an ongoing global discussion using social media, such as Twitter and Facebook [36].

Many teachers in the 21st century put learners first, which is referred to as student-centred learning [37]. Although some pedagogues continue to lecture in this model, students are encouraged to learn through peer-to-peer interactions-a form of active learning as well as acculturation. The emphasis on rote memorization has been supplanted by social forms of learning. Educators recognize it is more difficult for one person to teach 30 students simultaneously than it is to empower students to share their learning.

In health programs around the world, clinical instructors teach some subject content by lecturing (also known as didactic teaching) but also get students to meet together to dis- 
cuss hypothetical patient cases [38]. Some rote-learning will always be required in higher education, but memorization is increasingly secondary to learning how to think critically and work with others.

Interestingly, learners in behavioural models confront problems of various kinds when the stimuli-response patterns that they have learned do not occur in the same sequence each time, resulting in a "cognitive disconnect". Some workers trained to respond to certain cues on the job, for example, cannot exercise judgment if something unforeseen happens. It could be argued that teachers handicap their students when they teach exclusively based on "cueing".

Another criticism of behaviourism pertains to intrinsic motivation. Being self-motivated is critical to lifelong learning, but if someone is trained to accomplish tasks and get rewards, they become externally motivated. Worse, they do not think for themselves [39].

\section{What is constructivism?}

Constructivism claims that learners construct their own learning by building on previous knowledge, systems, or mental schema [40].

Constructivists believe that learners construct their own meaning and knowledge when given the chance to do so. When confronting new information, especially online, learners adjust their schema or previous knowledge to suit the new situation. Knowledge is not something transmitted but created by the learners themselves. The teacher's role in this model is to guide and facilitate, not to control learning [40].

There are three main types of constructivism: $(i)$ the cognitivist model, where a change in knowledge is constructed by learners and stored in the brain as information processes (as in a computer); (ii) the radical model, which focuses on what is or has been experienced by the learning activity; and (iii) the social model, a combination of the first two, where the "social nature of knowledge" is emphasized [41].

All three types of constructivist learning emphasize the importance of a learner's individual experiences in making sense of the learning activity. However, it must be pointed out that each type of constructivism takes a slightly different view of the process [42].

\section{Influential constructivists}

One of the major figures in education is the American John Dewey (1859-1952). He believed that teachers should not focus on teaching students facts or passing information along but helping them to "think for themselves" [43]. His educational reforms included an emphasis on experiential learning ("learning by doing") and reflecting on experiences for deep learning. Later constructivists such as Donald Schon referred to this powerful adjunct to learning as reflective practice [40].

Swiss psychologist Jean Piaget (1896-1980) proposed a constructivist theory of two parts: $(i)$ an "ages and stages" aspect where learners pass through cognitive stages according to age; and (ii) most learners develop cognitively in stages by introduction to the learning activity, getting assistance, testing the skills learned, and finally reaching a place of accomplishment [44].
Russian psychologist Lev Vygotsky (1896-1934) stressed the importance of a learner's cultural and social background in learning [45]. Different cultures stress different kinds of social interactions and learners are products of their environment. His belief that sociocultural influences are critical to learning challenges Piaget's theory that learning takes place in stages.

The gap between a student's existing ability and what she/he can learn with the guidance of an adult or a more capable peer is what Vygotsky called the "zone of proximal development (ZPD)" [46].

Health librarians can guide users through searching, model certain skills, and help learners through the zone of proximal development. Move your learners into "the zone" by getting them to frame their own understanding of concepts and by modeling best practices.

\section{Critique of constructivism}

Constructivist ideas have not always been accepted by educators. Undirected learning can be aimless and a waste of time [46]. Further, how can you construct knowledge of database searching if you are a novice? Where would you start? Doesn't this material have to be presented first as a basis of understanding? This is the biggest challenge of most constructivist teaching: how do you get all of your end-users on the same page in terms of basic content for your classes?

Piaget and other constructivists theorized that a lot of human learning takes place by trial and error-think of the idea of child's play and how creative it is [47]. How can health librarians incorporate the idea of trial and error in search workshops? Simply by offering some free time to do so.

Today, the idea of play is influential in education and in the workplace. Google permits its employees to learn things on their own and "try out new things" for up to $20 \%$ of their day [48]. However, this can cause time-management problems and lead to a lack of cooperation in team-based projects as it tends to emphasize individualism over collective needs.

It is critical to remember that constructivists believe students are less likely to retain information if they receive it passively. When listening to a lecture for example, students do not learn how to think critically about the ideas presented, and consequently they are not engaged intellectually; they may even grow bored. The challenge of constructivist models is that learners must be eager to learn, and, as most health librarians know, not all learners are motivated to learn. Often, we need to find a way to encourage motivation.

My own experience with constructivist teaching is that it requires some "letting go" of control in the classroom and that it yields some exciting results. As teachers, it can be difficult to trust that students can build their understanding without us. But in order for constructivist approaches to succeed, learners must be committed, have a high level of maturity and time-management skills, especially for group work.

With a health librarian there as a guide, a group of advanced MEDLINE searchers might benefit most from a constructivist approach, for example, because they can teach each other the skills and shortcuts they deem most useful. 


\section{What is situated learning?}

Situated learning is learning in contexts that reflect the way knowledge and skills will be used in real life [49].

Situated learning (or situated cognition) focuses on learning by doing in context and grounded in everyday life; it owes a lot to constructivist principles [49]. Two examples of situated (literally "in situ") learning are apprenticeships and practicum experiences in various health professions. In gaining their practical work experience, some student health librarians are able to practice their PubMed search skills when they are mentored by an experienced health librarian. But by working with a pharmacist or nurse (or any clinician for that matter) on a specific search problem (or case), their learning is more meaningful and put into context. In my experience, learning in authentic contexts can often be a trigger for much faster learning.

In situated learning, what is learned is transferable but requires "participation, engagement, negotiation, and contribution to the practice of a community" [50]. In a teaching hospital, for example, clinicians, medical students, librarians, and other health professionals contribute to a community of practice $(\mathrm{CoP})$, which is an aspect of informal learning discerned in this theory.

\section{Influential situated learning theorists}

Jean Lave and Etienne Wenger, two of the leaders in the situated cognition movement, see learning as "an act of creation" and co-creation (with others). Many rich, social interactions that occur between like-minded individuals are what they call a community of practice $(\mathrm{CoP})$. A CoP is defined as "groups of people who share a concern, a set of problems, or a passion about a topic, and who deepen their knowledge and expertise in this area by interacting on an ongoing basis" [51].

CoPs are defined along three dimensions: (1) what is the community about - its joint enterprise as understood and continually renegotiated by its members; (2) how does it function - mutual engagement that bind members together into a social entity; and (3) what capability has it produced the shared repertoire of communal resources (routines, sensibilities, artifacts, vocabulary, styles, etc.) that members develop over time [52].

Similarly, Brownet al. see CoPs as groups of people who are "learning knowledge and skills in contexts that reflect the way they will be used in real life" [53].

\section{Critique of situated learning}

Situated learning sounds novel, but as an approach to learning, it is not new. Of course, it places learning in a context that many professions expect, including librarianship, where learning occurs wherever librarians are working. It is also worth emphasizing that being submerged in the culture of a profession enhances learners' competencies and facilitates self-efficacy beliefs [53].

Situated learning is not a panacea, however. Acculturation, the "experience of participating and engaging in daily life" [54], can take time to develop organically; it doesn't happen overnight. Moreover, some kinds of skills are better learned alone before integration into professional practice because individual "lone rangers" can hold team progress back. Take musical groups such as choirs or symphony or- chestras. Considerable time is spent learning how to sing or play alone before coming together and learning how to work with others-success does not come otherwise.

Wenger reminds us though that "not everything called a community is a community of practice. A neighborhood is considered a community but it is not a community of practice" [55]. Other critics of situated learning say that not all learning requires a meaningful context or a community. New skills can be learned out of context by reading a book or teaching oneself.

\section{Conclusion}

The next time you plan to teach a PubMed session at your hospital or university computer lab, the three learning theories discussed here may trigger a number of questions: will I try a behavioural or a constructivist approach in my session? Perhaps you will plan to demonstrate and talk about the basics of PubMed searching and move on to getting your users to work on specific searches in small learning groups.

Between your teaching sessions, how will you encourage your users to keep learning? Can you suggest ways to move your learners towards more of a community of practice? Will you embed yourself on a regular basis in the CoP? At the very least, knowing the basic principles of these theories should help you to explore alternatives and attach pedagogical terms to your approach.

I have found that many health librarians have an intuitive sense of how to teach, and many excel at it. Others like to use the evidence to inform their teaching and use the literature to design classes. But by using learning theory-rather than experience and evidence alone-we can move towards a more integrated teaching model. At the very least, using a blended approach of theory, experience, and intuition is more holistic than using any individual method alone.

Consider your long-term planning in terms of your teaching. What goals are you trying to achieve in your instructional programs? Are you looking to teach discrete information skills or something more durable? In the current digital landscape, a critical issue may be how we can actively foster learning cultures in our organizations given the speed of change in our libraries and the pressures introduced by newer information technologies.

These and other practical questions will be the focus in the second column of this series where I will explore how to apply learning theories to the actual design of library workshops and teaching sessions.

\section{References}

1. Giustini D. Shifts of perspective: a preliminary look at constructivism, phenomenography and socio-cultural learning theories. Available from: http://weblogs.elearning.ubc.ca/ googlescholar/ADHE_541_Giustini.pdf.

2. Alexander B. Web 2.0: a new wave of innovation for teaching and learning? Educause review. 2006;41(2):33-44. Available from: http://www.educause.edu/ir/library/pdf/erm0621.pdf.

-3. Dee CR. Digital reference service: trends in American health science libraries. Med Ref Serv Q. 2005;24(1):19-27. 
4. Tu F. Knowledge and skills required to provide health information-related virtual reference services: evidence from a survey. J Med Libr Assoc. 2007 Oct;95(4):458-61.

-5. Cobus L. Integrating information literacy into the education of public health professionals: roles for librarians and the library. J Med Libr Assoc. 2008 Jan;96(1):28-33.

6. Hatala R, Keitz SA, Wilson MC, Guyatt G. Beyond journal clubs: moving toward an integrated evidence-based medicine curriculum. J Gen Intern Med. 2006 May;21(5):538-41.

7. Burr Oliver K, Dalrymple P, Lehmann HP, McClellan DA, Robinson KA, Twose C. Bringing evidence to practice: a team approach to teaching skills required for an informationist role in evidence-based clinical and public health practice. $J$ Med Libr Assoc. 2008;96(1):50-7.

8. Julien H, Pecoskie JL. The teaching role: experiences of librarians in Canada. A presentation at the WILU conference; 2008 May 13-15; Kelowna, B.C.

9. Carroad EG, McGregor G. The teaching role of the health science library. In: Darling L, Colaianni LA, Bishop D, editors. Handbook of medical library practice. 4th ed. v. 1. Chicago: Medical Library Association, 1982:237-71.

10. Homan JM, McGowan JJ. The Medical Library Association: promoting new roles for health information professionals. $J$ Med Libr Assoc. 2002 Jan;90(1):80-5.

11. Brettle A. Information skills training: a systematic review of the literature. Health Info Libr J. 2003 Jun;20 Suppl 1:3-9.

12. Koufogiannakis D, Wiebe N. Effective methods for teaching information literacy skills to undergraduate students: a systematic review and meta-analysis. Evidence Based Library and Information Practice. 2006;1(3):3-43.

13. Peacock JA. Teaching skills for teaching librarians: postcards from the edge of the educational paradigm. Australian Academic \& Research Libraries. 2001;32(1).

14. McNamara D, Core J. Teaching for learning in libraries and information services: a series of educational development workshops. The EduLib Project. UK: University of Hull, 1998.

15. American Library Association. Presidential Committee on Information Literacy. Chicago, Ill.: American Library Association, 1989.

16. Association of American Medical Colleges. Medical school objectives project: medical informatics objectives. Washington, D.C.: Association of American Medical College, 1998.

17. Huitt W, Hummel J. An overview of the behavioral perspective. Educational Psychology Interactive [Web site]. Valdosta, Ga.: Valdosta State University, 2006. Available from: http://chiron.valdosta.edu/whuitt/col/behsys/behsys.html.

18. Skinner BF. The behavior of organisms. New York: AppletonCentury-Crofts, 1938.

19. Rohe DE, Barrier PA, Clark MM, Cook DA, Vickers KS, Decker PA. The benefits of pass-fail grading on stress, mood, and group cohesion in medical students. Mayo Clin Proc. 2006 Nov;81(11):1443-8.

20. Chung QB. Sage on the stage in the digital age: the role of online lecture in distance learning. Electronic Journal of $e$ Learning. 2005;3(1):1-14.
21. Whatley J, Ahmad A. Using video to record summary lectures to aid students' revision. Interdisciplinary Journal of Knowledge and Learning Objects. 2007;3:185-96.

22. Friere P. Pedagogy of the oppressed. New York: Continuum, 2007.

23. Vygotsky L. Mind in society: The development of higher psychological processes. Cambridge: Harvard University Press, 1978.

24. Lave L, Wenger E. Situated learning: legitimate peripheral participation. Cambridge: University of Cambridge Press, 1991.

25. Pavlov IP, Anrep GV. Conditioned reflexes. Mineola, N.Y.: Dover Publications, 2003.

26. Scheepers. D. Learning theories: behaviorism. 2000. Available from: http://hagar.up.ac.za/catts/learner/2000/scheepers_md/ projects/loo/theory/behavior.html.

27. Watson JB. Psychology from the standpoint of a behaviorist. Philadelphia: Lippincott, 1919.

28. Watson JB, Rayner R. Conditioned emotional reactions. J Exp Psychol. 1920;3(1):1-14.

29. Hock R. Forty studies that changed psychology: explorations into the history of psychological research. 5th ed. New Jersey: Prentice Hall, 2005.

30. Skinner BF. The behavior of organisms. New York: AppletonCentury Co., 1938.

31. McConaghy N, Barr RF. Classical, avoidance and backward conditioning treatments of homosexuality. $\mathrm{Br} J$ Psychiatry. 1973 Feb;122(567):151-62.

32. Skinner BF. Teaching machines. 1958. In: Ely DP, Plomp T, editors. Classic writings on educational technology. Englewood, Colo: Libraries Unlimited, 1996.

33. Anderson RP, Wilson SP, Livingston MP, LoCicero AD. Characteristics and content of medical library tutorials: a review. $J$ Med Libr Assoc. 2008 Jan;96(1):61-3.

34. Bonk C. Introducing the R2D2 model: online learning for the diverse learners of world. Distance education. 2006;27(2):249-64.

35. Cooper J, Weaver KD. Gender and computers: understanding the digital divide. Mahwah, N.J.: Erlbaum Associates, 2003.

36. Brown JS. Growing up digital: how the web changes work, education, and the ways people learn. USDLA Journal. 2002 Feb;16(2). Available from: http://www.usdla.org/html/journal/ FEB02_Issue/article01.html.

37. Henson KT, Borthwick P. Matching styles: a historical look. Theory into Practice. 1984 Winter;23(1):3-9.

38. Christianson CE, McBride RB, Vari RC, Olson L, Wilson HD. From traditional to patient-centered learning. Acad Med. 2007 Nov;82(11):1079-88.

39. Scheepers D. Learning theories: behaviorism. 2000. Available from: http://hagar.up.ac.za/catts/learner/2000/scheepers_md/ projects/loo/theory/behavior.html.

40. Scheepers D. Learning theories: constructivism. 2000. Available from: http://hagar.up.ac.za/catts/learner/2000/scheepers_md/ projects/loo/theory/construct.html. 
41. Winn WD, Synder D. Cognitive perspectives in psychology. In: Jonassen D, editor. Handbook of research on educational communications and technology. New York: Oxford University Press; 1996.

42. Darkenwald GG. Enhancing the adult classroom environment. New Directions for Continuing Education. 1989;43:67-75.

43. Dewey J. The need for a philosophy of education: a new era in home and school. World Education Fellowship 1934;XV:21114.

44. Huitt W, Hummel J. Piaget's theory of cognitive development. Educational Psychology Interactive. Valdosta, Ga.: Valdosta State University, 2003. Available from: http://chiron.valdosta. edu/whuitt/col/cogsys/piaget.html.

45. Newman F, Holzman L. Lev Vygotsky: revolutionary scientist. London: Routledge, 1993.

46. Vygotsky L. Mind in society: The development of higher psychological processes. Cambridge: Harvard University Press, 1978.

47. Berk LE. Vygotsky's theory: the importance of make-believe play. Young child. 1994;50(1):30-9.
48. Mediratta B. The Google way: give engineers room. The New York Times. 2007 Oct 21. Available from: http://www.nytimes. com/2007/10/21/jobs/21pre.html.

49. Brill JM. Situated cognition. In Orey M, editor. Emerging perspectives on learning, teaching, and technology, 2001. Available from: http://www.coe.uga.edu/epltt/situatedcognition.htm.

50. Wenger E. Communities of practice: learning, meaning and identity. Cambridge: University Press, 1998.

51. Lave L, Wenger E. Situated learning: legitimate peripheral participation. Cambridge: University of Cambridge Press, 1991.

52. Smith MK. Communities of practice. Encyclopedia of Informal Education. 2003. Available from: http://www.infed.org/ biblio/communities_of_practice.htm.

53. Brown JS, Collins A, Duguid P. Situated cognition and the culture of learning. Educational Researcher. 1989;18(1):32-42.

54. Lave L, Wenger E. Situated learning: legitimate peripheral participation. Cambridge: University of Cambridge Press, 1991.

55. Wenger E. Supporting communities of practice: a survey of community-oriented technologies [Web site]. 2001. Available from: www.ewenger.com/tech. 
This article has been cited by:

1. 2010. Full Issue in PDF / Numéro complet enform PDF. Journal of the Canadian Health Libraries Association 31:1, 1-24. [Citation] [PDF] [PDF Plus]

2. Dean Giustini. 2010. Evidence-based teaching (EBT) and health librarians: some questions and considerations. Journal of the Canadian Health Libraries Association 31:1, 7-10. [Citation] [PDF] [PDF Plus]

3. Greg Rowell, Dean Giustini. 2009. Are constructivist approaches in teaching health librarians effective? A reflective case study of teaching a course in health librarianship. Journal of the Canadian Health Libraries Association 30:4, 139-143. [Citation] [PDF] [PDF Plus]

4. Dean Giustini. 2009. Tipping point(s): informal learning for health librarians in an economic downturn. Journal of the Canadian Health Libraries Association 30:3, 113-116. [Citation] [PDF] [PDF Plus]

5. Dean Giustini. 2009. Utilizing learning theories in the digital age: from theory to practice. Journal of the Canadian Health Libraries Association 30:1, 19-25. [Citation] [PDF] [PDF Plus] 